Volkan Yumuk*

\title{
EASO COLLABORATING CENTERS FOR OBESITY MANAGEMENT (COMS)
}

Obesity is a global epidemic and the most prevalent metabolic disease in the world. Preventive and treatment measures taken are still not adequate and these services are still not equally widespread. In response to this situation, EASO has developed a network of "accredited specialised obesity centers", where the quality and efficacy of the care offered to patients are of the highest standards. Under the EASO Collaborating Centers for Obesity Management (COM) scheme, these centers will be accredited in accordance with accepted European and academic guidelines.

\section{Mission of EASO-COMs:}

- Implement state-of-the art evidence-based care for obese patients

- Monitor all obesity- related medical conditions and risk factors

- Provide high quality patient and public information

- Improve access to care pathways by optimizing referral processes and developing close working between levels of care

- Develop comprehensive multidisciplinary local collaboration

- Facilitate, and empower patients to make healthy lifestyle changes: develop therapeutic education

- Educate staff about treating patients with obesity

- Encourage development of and support Patient Associations, by sharing experience and expertise

- Offer or collaborate with preventive care services

Prof. dr, Department of Medicine, Division of Endocrinology and Metabolism, Istanbul University Cerrahpasa Medical Faculty, Istanbul, Turkey 
- Promote obesity related knowledge and awareness among the public and health care providers

- Improve the collaboration interface between clinical researchers and scientists

- Integrate health care, teaching and research

- Facilitate clinical research projects

- Contribute to a network of EASO-COMs across Europe with close collaboration and communication

\section{Accredited centers will have the opportunity to:}

- Contribute to the development of EASO pan-European protocols for the evaluation of obese patients

- Contribute to the development of consensus statements/guidelines on specialised aspects of obesity management

- Contribute to obesity education across Europe

- Participate in an EASO led pan-European scientific/clinical exchange programme

- Participate in EASO facilitated Clinical Trials and Pilot Studies

- Participate in EASO coordinated research projects

- Participate in COM 'Summit Meetings' at each ECO (European Congress on Obesity)

- Access and contribute to an EASO pan-European system of data collection and analysis

- Access a web-based COM community where each center can post job vacancies and highlight the key capabilities and features of the center

Many centers across Europe should apply and when eligable should become a part of this high standard network in order to promote obesity prevention and management. Updating knowledge, improving skills, and contributing to research in the field of obesity will definitely strengthen European struggle against obesity and improve public health.

\section{References}

Tsigos C., Hainer V., Basdevant A et al., Criteria for EASO-collaborating Centres for obesity management, Obesity Facts 2011; 4:329-333.

http://www.easo.org/coms 
Volkan J umuk*

\section{EASO CENTRI ZA VOĐENJE GOJ AZNOSTI (COMs)}

Gojaznost je globalna epidemija i najčešća metabolička bolest u svetu. Do sada preduzete preventivne i terapijske mere nisu bile dovoljne, a odgovarajuće službe nisu podjednako raspoređene. U odgovoru na takvo stanje, EASO je razvio mrežu „,akreditovanih specijalizovanih centara za gojaznost”, u kojima kvalitet i uspešnost zaštite pružene pacijentima imaju najviše standarde. Na osnovu plana Centara za saradnju u vođenju gojaznosti (COMs) Evropskog udruženja za proučavanje gojaznosti (EASO), ovi centri će biti akreditovani u skladu sa usvojenim evropskim i akademskim preporukama.

\section{Zadatak Centara za saradnju u vođenju gojaznosti Evropskog udruženja za proučavanje gojaznosti:}

- Ostvariti savremenu zdravstvenu zaštitu gojaznih pacijenata zasnovanu na dokazima;

- Beležiti sva medicinska stanja vezana za gojaznost i rizične faktore;

- Obezbediti kvalitetne informacije za pacijenta i javnost;

- Poboljšati pristup pacijenta zdravstvenoj zaštiti unapređenjem postupka upućivanja i boljom saradnjom među različitim nivoima zaštite;

- Razviti široku multidisciplinarnu saradnju na nivou centra;

- Podstaći i osposobiti pacijente da usvoje zdrav način života: razviti edukativni pristup u terapiji;

- Obučiti osoblje o načinu lečenja gojaznih pacijenata;

- Ohrabriti osnivanje i podržati Udruženja pacijenata kroz razmenu iskustava i veština; 
- Razviti saradnju sa primarnom zdravstvenom zaštitom;

- Šriti znanje i svest o gojaznosti među javnim i zdravstvenim radnicima;

- Poboljšati polje saradnje između istraživača i naučnika;

- Objediniti zdravstvenu zaštitu, obrazovanje i istraživanje;

- Podsticati kliničke istraživačke projekte;

- Pružiti doprinos mreži Centara za saradnju u vođenju gojaznosti širom Evrope jačanjem komunikacija i podrške.

\section{Akreditovani centri će imati priliku da:}

- Doprinesu razvoju EASO - panevropskih protokola za evaluaciju gojaznih pacijenata;

- Doprinesu razvoju opšteprihvaćenih saopštenja / preporuka o posebnim aspektima vođenja gojaznosti;

- Doprinesu edukaciji o gojaznosti širom Evrope;

- Učestvuju u panevropskom naučnom / kliničkom programu razmene koji vodi EASO;

- Učestvuju u kliničkim ispitivanjima i pilot studijama koje podržava EASO;

- Učestvuju u istraživačkim projektima koje koordiniše EASO;

- Učestvuju na Samitu Centara za saradnju u vođenju gojaznosti na svakom Evropskom kongresu o gojaznosti (ECO);

- Pristupe i doprinose panevropskom sistemu sakupljanja i analize podataka koje vodi EASO;

- Pristupe web - zajednici Centara za saradnju u vođenju gojaznosti, u kojem svaki centar može izneti slobodna radna mesta i istaći ključne odlike i mogućnosti centra.

U cilju promocije prevencije i vođenja gojaznosti, mnogi centri širom Evrope treba da se prijave $i$, kada ispune uslove, postanu deo mreže centara visokog standarda. Praćenje novih saznanja, unapređenje veština i doprinos istraživanju u oblasti gojaznosti svakako će ojačati evropsku borbu protiv gojaznosti i poboljšati javno zdravlje.

\section{Literatura}

Tsigos C., Hainer V., Basdevant A et al., Criteria for EASO-collaborating Centres for obesity management, Obesity Facts 2011; 4:329-333.

http://www.easo.org/coms 